\title{
ANTONIETTA SANNA, Paul Valéry traducteur de Leonardo da Vinci. Lecture, interprétation, création
}

\section{Paola Cattani}

\section{(2) OpenEdition}

\section{Journals}

\section{Edizione digitale}

URL: https://journals.openedition.org/studifrancesi/23027

DOI: 10.4000/studifrancesi.23027

ISSN: 2421-5856

\section{Editore}

Rosenberg \& Sellier

\section{Edizione cartacea}

Data di pubblicazione: 1 avril 2020

Paginazione: 211

ISSN: 0039-2944

\section{Notizia bibliografica digitale}

Paola Cattani, «AntonietTa sanna, Paul Valéry traducteur de Leonardo da Vinci. Lecture, interprétation, création», Studi Francesi [Online], 190 (LXIV | I) | 2020, online dal 01 mai 2020, consultato il 03 août 2021. URL: http://journals.openedition.org/studifrancesi/23027 ; DOI: https://doi.org/10.4000/ studifrancesi.23027

Questo documento è stato generato automaticamente il 3 août 2021

\section{(c) $($ ) $(9)$}

Studi Francesi è distribuita con Licenza Creative Commons Attribuzione - Non commerciale - Non opere derivate 4.0 Internazionale. 


\title{
ANTONIETTA SANNA, Paul Valéry traducteur de Leonardo da Vinci. Lecture, interprétation, création
}

\author{
Paola Cattani
}

\section{NOTIZIA}

ANTONIETTA SANNA, Paul Valéry traducteur de Leonardo da Vinci. Lecture, interprétation, création, Paris, Éditions des Archives Contemporaines, 2019, 144 pp.

1 Il volume pubblicato da Antonietta Sanna porta meritevolmente alla luce un progetto giovanile di Paul Valéry poco noto anche agli specialisti di questo autore, e purtuttavia di estremo interesse, per i suoi contenuti e perché permette di conoscere meglio le prime fasi della produzione valéryana - gli anni del famoso "silenzio poetico".

Dopo aver pubblicato la celebre Introduction à la méthode de Léonard de Vinci nel 1895, tra il 1905 e il 1908 Valéry si dedica alla traduzione (o piuttosto alla rielaborazione e riscrittura, come Antonietta Sanna mette in rilievo) di alcuni frammenti dei manoscritti di Leonardo, con l'obiettivo di confezionare un volume che presenti al pubblico francese dei passaggi poco noti (perché esclusi dalla fortunatissima edizione dei Frammenti letterari e filosofici curata da Edmondo Solmi e più volte ripubblicata tra 1899 e 1904) dei Carnets leonardeschi conservati alla Bibliothèque de l'Institut a Parigi. Il volume curato da Antonietta Sanna presenta per la prima volta queste traduzioni/ riscritture di Valéry (ottantasette in tutto), riscostruite secondo un approccio di critica genetica.

Nella prima parte del volume, un denso saggio introduttivo ricostruisce in primo luogo il contesto in cui prende forma il dialogo che Valéry rinnova con Leonardo nei primi anni del secolo: dal punto di vista del percorso intellettuale di questo autore, impegnato in una fase di ricognizione e ricerca che getterà $i$ fondamenti della sua produzione successiva, e più in generale, dal punto di vista del dibattito critico coevo $\mathrm{e}$ 
della ricezione di Leonardo in Francia. Sono così messe in evidenza le ragioni del successo dell'artista italiano nella Francia della congiuntura tra i due secoli, e soprattutto è ben descritta un'evoluzione fondamentale in atto, cui Valéry partecipa, e che tende a sostituire all'immagine di un Leonardo decadente, diffusasi nel corso del XIX secolo, il mito dell'uomo dalla mentalità scientifica. In seguito, l'introduzione studia alcuni elementi fondamentali della "teoria della traduzione" valéryana, ricostruita in riferimento anche ad altri cantieri traduttivi di Valéry, precedenti e successivi. Per Valéry tradurre significa comprendere e replicare il movimento del pensiero dell'opera-fonte, fino a stabilire con esso una relazione fusionale, in grado di originare un atto creativo nuovo. Emerge così benissimo che l'esercizio su Leonardo rappresenta per Valéry anzitutto un lavoro su di sé e sulle proprie capacità artistiche, oltre che una meditazione sull'atto "poietico", entrambi sollecitati dall'incontro con un grande spirito con il quale Valéry avverte un'affinità elettiva.

Da una tale relazione fusionale con Leonardo escono rafforzate, da un lato, la determinazione ad avanzare nell'avventura intellettuale dei Cahiers, che trovano in effetti punti di contatto sostanziali con i Carnets leonardeschi; da un altro lato, una meditazione che si rivelerà per Valéry essenziale fino agli anni Quaranta, sulle trasformazioni impresse all'esprit dalle trasformazioni dell'età contemporanea. Progettando di dedicare il suo volume all'«Idée de Léonard de Vinci entièrement déduite de ses sentences», Valéry è interessato infatti a meditare soprattutto, come Antonietta Sanna osserva, la scomparsa dell'uomo universale nell'era moderna, e i destini di quello che egli considera insieme a Goethe un modello per la civiltà europea. 